\title{
THE PROGNOSTIC SIGNIFICANCE OF THE TRIRADIATE CARTILAGE IN SUPPURATIVE ARTHRITIS OF THE HIP IN INFANCY AND EARLY CHILDHOOD
}

\author{
S. WIENTROUB, G. C. LLOYD-ROBERTS, M. FRASER \\ From the Hospital for Sick Children, Great Ormond Street, London
}

\begin{abstract}
The significance of damage to the triradiate growth plate of the acetabulum in suppurative arthritis of the hip in children is considered. Damage leading to premature arrest of growth correlates closely with severe damage to the femoral head. Sparing of the growth plate is associated with preservation of a mobile head. Late complications include the arrest of acetabular development.
\end{abstract}

Suppurative arthritis of the hip in infancy and early childhood inflicts permanent damage of variable severity if it is not treated promptly and aggressively (Paterson 1970). Damage is sometimes limited to the articular cartilage alone, but in neonatal infection there is commonly destruction and displacement of the joint. This often follows consistent patterns and presents opportunities for repair or reconstruction. Repair is possible when there is dislocation of the hip with an intact femoral neck, or a pathological fracture of the neck of the femur producing a pseudarthrosis with a mobile head within the acetabulum. When a fracture of the neck of the femur is associated with an adherent femoral head or when the head is destroyed, a decision may be made to attempt reconstruction by trochanteric arthroplasty (Weissman 1967) to perform an arthrodesis later, or to abandon treatment (Lloyd-Roberts and Ratliff 1978).

It would be helpful to be able to distinguish between these favourable and unfavourable situations at an early age so that treatment may be planned accordingly. The aim should be to operate before walking begins in patients with favourable signs in order to prevent further displacement. In the presence of unfavourable signs there is less urgency. Unfortunately this distinction is seldom possible at this age. The radiographic appearance of the proximal femur is rarely helpful after neonatal disease because skeletal immaturity coupled with decalcification due to infection means that the significant structures are radiolucent. Furthermore, even when the head is radiopaque, its mobility cannot be assessed and arthrography is not of assistance (LloydRoberts 1960). It is, however, helpful to assess the state of the triradiate cartilage of the acetabulum when, for some reason, early operation has been withheld.

\section{MATERIAL AND RESULTS}

The case records and radiographs of 31 patients who had suffered suppurative arthritis of the hip were studied and divided into two groups on the basis of the presence or absence of radiological signs of damage to the triradiate cartilage.

There were 10 patients in the first group, eight of whom had had neonatal infection. The clinical details, radiological signs and findings at operation in this group are presented in Table I, which shows that in all patients the head of the femur was absent or ankylosed. Figures 1,2 and 3 show premature closure of the growth plate in two of these patients. There were 21 patients in whom the growth plate was spared. One patient showed dislocation in continuity, 10 patients had pseudarthrosis with a mobile viable head (Figs 4 and 5) and 10 healed spontaneously with stability and mobility of the hip though all showed either coxa magna, coxa vara or coxa valga due to injury of the growth plate of the femoral head.

The integrity of the triradiate cartilage of the acetabulum appears to be a reliable indicator of the state of the femoral head. When there is damage and the epiphysial plate is seen to be narrowed and irregular, the femoral head will be found to be adherent or destroyed and the plate will close prematurely. When the acetabular growth plate is undamaged it may be assumed that the femoral head is present and that, if it is within the acetabulum, it is mobile.

S. Wientroub, MD, Consultant Orthopaedic Surgeon, Ichilov Hospital, Tel Aviv and Sackler School of Medicine, Tel Aviv, Israel.

G. C. Lloyd-Roberts, MCh, FRCS, Orthopaedic Surgeon, The Hospital for Sick Children, Great Ormond Street, London WC1, England. M. Fraser, FRCS, Orthopaedic Registrar, Royal National Orthopaedic Hospital, Great Portland Street, London W1N 6AD, England. Requests for reprints should be addressed to Mr G. C. Lloyd-Roberts.

(1) 1981 British Editorial Society of Bone and Joint Surgery 0301-620X/81/2044-0190\$2.00 


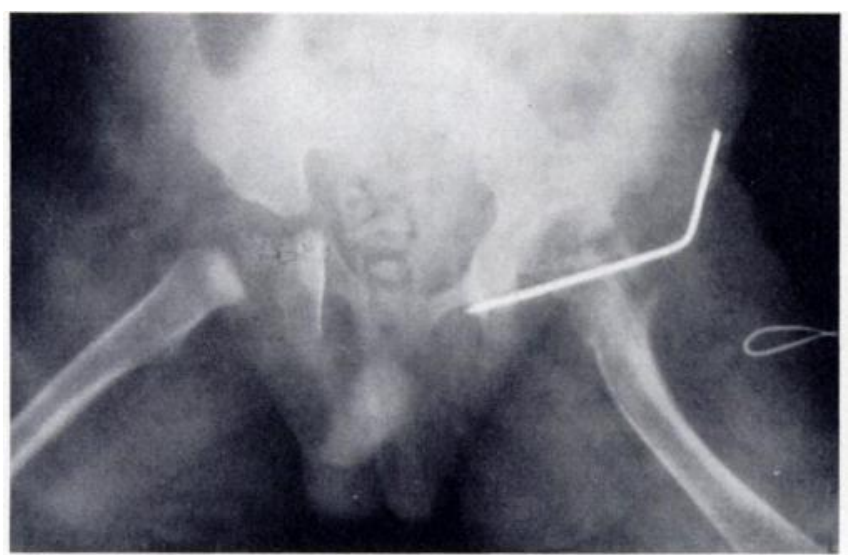

Fig. 1

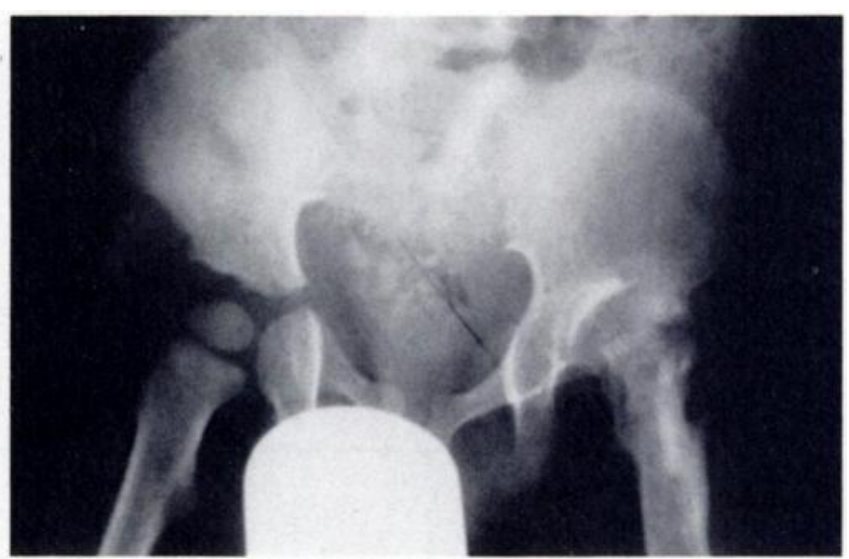

Fig. 2

Case 7. Figure 1-Radiograph taken during operation. This shows that the acetabular growth plate had already closed at one year of age. Figure 2-Radiograph 18 months later which confirms complete closure of the growth plate.

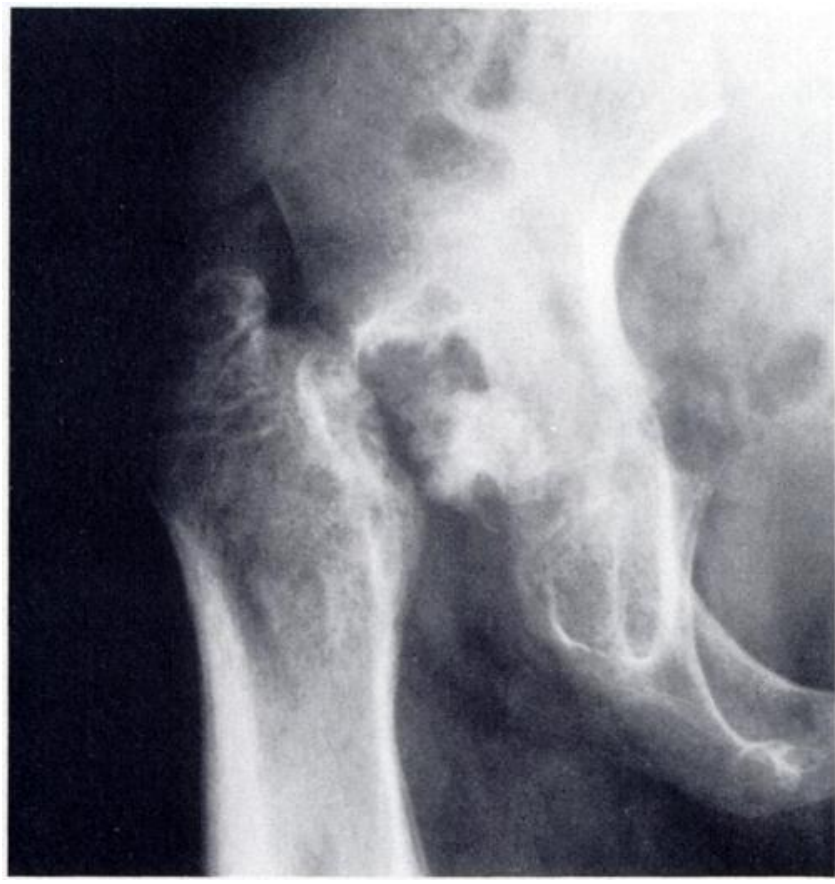

Fig. 3

Case 9. Radiograph at 6 years 5 months. The acetabular growth plate is closed, the head is adherent to the acetabulum and there is a pseudarthrosis of the neck of the femur.

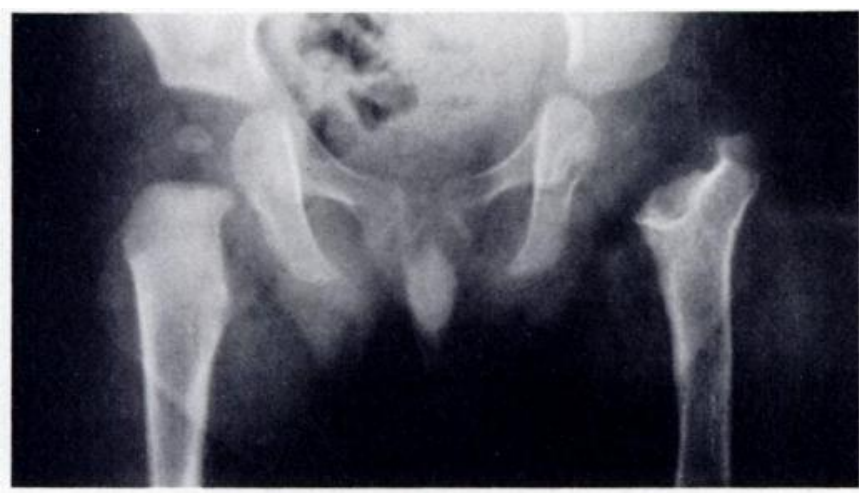

Fig. 4

\section{DISCUSSION}

Dias, Tachdjian and Schroeder (1980) have recently reported a patient with premature closure of the triradiate cartilage in whom an unsuccessful attempt was made to restore growth potential. This patient is of interest because the femoral head remained mobile though enlarged. This would seem to conflict with our findings. However, there was no evidence in this patient that the joint itself was primarily involved during neonatal septicaemia. The intrapelvic operation carried out failed because of infection, and tomography before operation suggested that pre-existing disease affected the inner table of the pelvis. It is suggested therefore that closure of the growth plate was secondary to osteomyelitis of the pelvis rather than to suppurative arthritis of the hip. This suggestion has been accepted by one of the authors (MOT) and he has since seen a patient with a similar lesion. We also have seen one such patient.

We believe that when infection involves the joint, the integrity of the triradiate growth plate is a valuable indication of the state of the femoral head. In this study we found that unequivocal radiographic evidence of

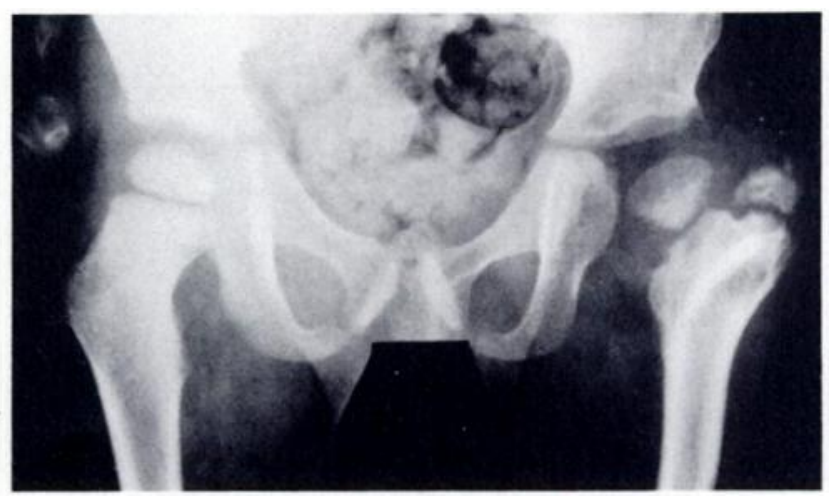

Fig. 5

Radiographs of a patient from the second group. Figure 4-The acetabular growth plate is open and the head is just visible. Figure $5-$ Four years later, after operation for grafting of the pseudarthrosis and an abduction osteotomy. The hip is stable and mobile and the acetabulum is developing well. 


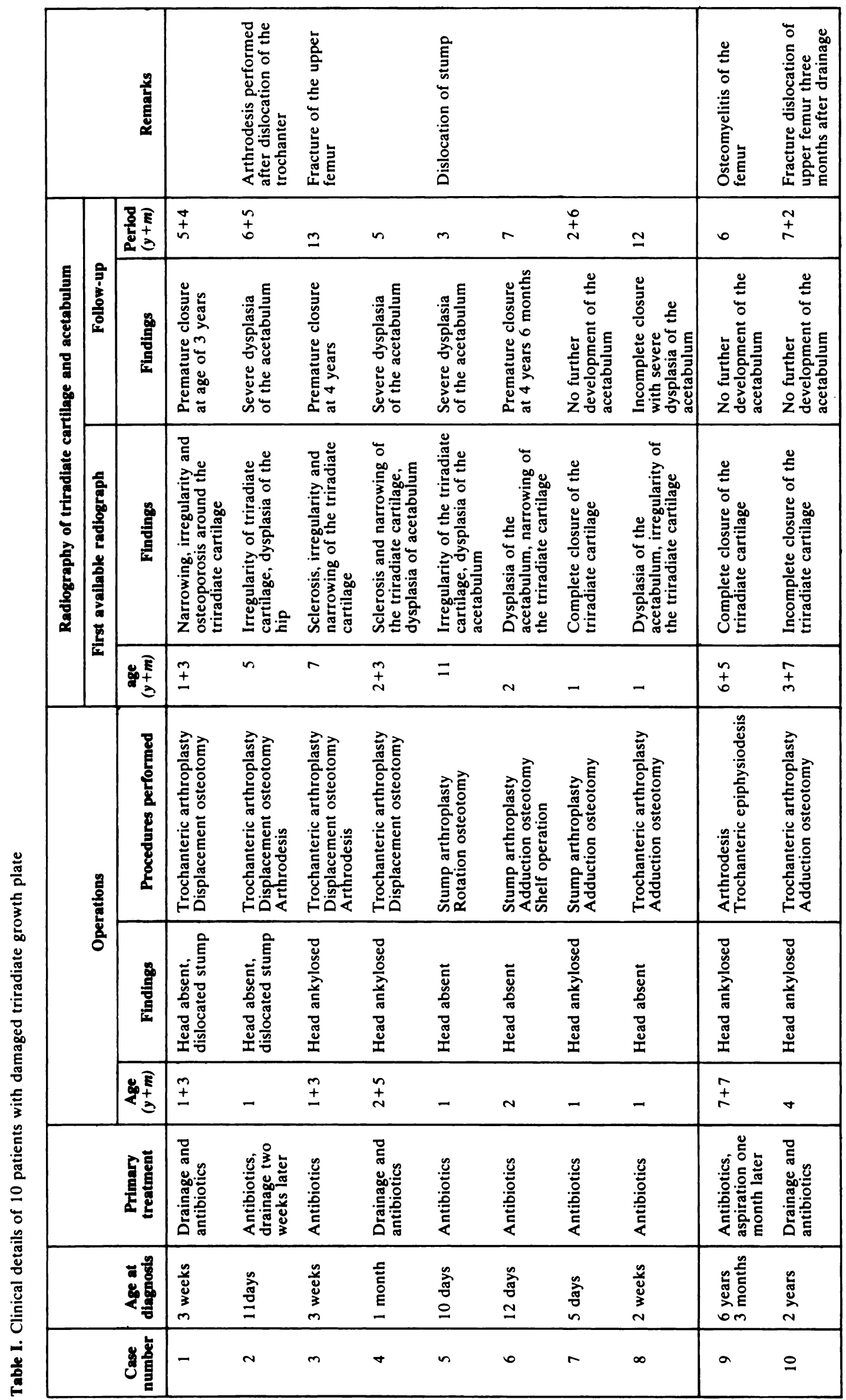




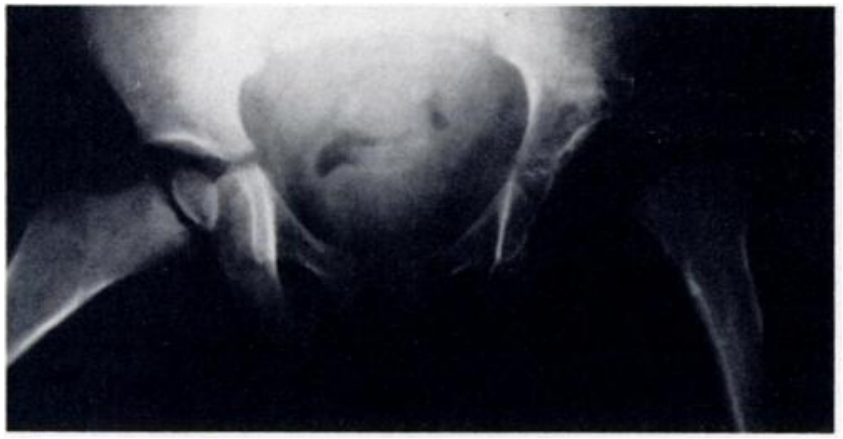

Fig. 6

Case 6. Radiograph showing that the acetabular growth plate is damaged. The head was destroyed and the acetabulum has failed to develop. damage to the growth plate was generally delayed for over a year in neonatal patients. It is preferable to explore these joints before the child starts walking, but at this age changes in the triradiate growth plate may not be obvious. We therefore propose in future to give special attention to this area using standard and computerised tomography in the hope that detection of damage will be possible at an earlier and more appropriate stage of management.

It must be emphasised that premature closure of the triradiate cartilage results in inhibition of acetabular growth (Fig. 6), and that when trochanteric arthroplasty has been performed there is likely to be need for reconstruction of the acetabulum at a later date.

Dr Schlomo Wientroub was supported by a grant from the Lewis Fellowship Fund, London.

\section{REFERENCES}

Dias L, Tachdjian MO, Schroeder KE. Premature closure of the triradiate cartilage. J Bone Joint Surg [Br] 1980;62-B:46-8.

Lloyd-Roberts GC. Suppurative arthritis of infancy: some observations upon prognosis and management. J Bone Joint Surg [Br] 1960;42-B:706-20.

Lloyd-Roberts GC, Ratliff AHC. Hip disorders in children. Postgraduate Orthopaedic Series. London: Butterworth \& Co, 1978:91-118.

Paterson DC. Acute suppurative arthritis in infancy and childhood. J Bone Joint Surg [Br] 1970;52-B:474-82.

Weissman SL. Transplantation of the trochanteric epiphysis into the acetabulum after septic arthritis of the hip. J Bone Joint Surg [Am] 1967;49-A:1647-51. 